\title{
Metabolic effects of sacubitril/valsartan: are they relevant in clinical practice?
}

\author{
Rafael de la Espriella-Juan', Juan Sanchis ${ }^{1,2}$, Antoni Bayés-Genís ${ }^{2,3,4}$, Julio Núñez ${ }^{1,2}$ \\ ${ }^{1}$ Department of Cardiology, Hospital Clínico Universitario, INCLIVA, Universitat de València, Valencia, Spain; ${ }^{2}$ CIBER Cardiovascular, Madrid, \\ Spain; ${ }^{3}$ Cardiology Service and Heart Failure Unit, Hospital Universitari Germans Trias i Pujol, Badalona, Spain; ${ }^{4}$ Department of Medicine, \\ Autonomous University of Barcelona, Barcelona, Spain \\ Correspondence to: Dr. Julio Núñez, MD, PhD. Department of Cardiology, Hospital Clínico Universitario, INCLIVA, Universitat de València, Avda, \\ Blasco Ibáñez 17, CP 46010, Valencia, Spain. Email: yulnunez@gmail.com. \\ Provenance: This is an invited Editorial commissioned by the Section Editor Yue Liu (The First Affiliated Hospital, Harbin Medical University, \\ Harbin, China). \\ Comment on: Engeli S, Stinkens R, Heise T, et al. Effect of Sacubitril/Valsartan on Exercise-Induced Lipid Metabolism in Patients with Obesity and \\ Hypertension. Hypertension 2018;71:70-7.
}

Submitted May 18, 2018. Accepted for publication Jul 02, 2018.

doi: $10.21037 /$ cdt.2018.07.05

View this article at: http://dx.doi.org/10.21037/cdt.2018.07.05

The burden of cardiometabolic diseases continues to rise worldwide (1). Obesity, insulin resistance, atherogenic dyslipidemia, hypertension and intra-abdominal adiposity are strongly interrelated and are crucial determinants of heart failure (HF) (2).

Natriuretic peptides (NPs) have long been recognized as important cardio-renal hormones given their key role in the regulation of sodium and water homeostasis as well as their ability to modulate cardiac inflammation, pathological growth, and secretion of aldosterone (3). However, recent evidence suggest that they are also potent metabolic hormones (4). They exert a strong lipolytic action in human adipocytes mediated by the intracellular activation of protein kinase $G$ which subsequently phosphorylates key proteins involved in the outflow of non-esterified fatty acids from adipocytes $(5,6)$. Intravenous infusions of human atrial NP (ANP) rapidly induced lipid mobilization and their oxidation, both in rest (7) and during exercise (8), suggesting a putative implication of NPs in the physiological control of lipid mobilization. Moreover, NPs also modulates the secretion of adipokines and cytokines involved in the pathogenesis of low-grade inflammation and insulin resistance observed in cardiometabolic syndrome (CMS) (9). Beyond their lipolytic properties, NPs are also involved in glucose homeostasis through several pathways. Among others, NP/cyclic guanosine monophosphate (cGMP) signaling directly increases pancreatic beta-cell mass and insulin secretion (10), enhance insulin sensitivity through upregulation of fat oxidation, increase mitochondrial biogenesis in skeletal muscle, and adiponectin production by adipose tissue (11-13). In addition, some reports suggest NPs reduce hunger and food intake through the suppression of fasting-induced ghrelin (an anorexigenic hormone secreted by the stomach) (14) and lowers postprandial glucose excursion by reducing gastric emptying and absorption (15).

Neprilysin (NEP) is a ubiquitous membranebound endopeptidase responsible for the breakdown of endogenous vasoactive peptides with favorable actions in HF, including the NPs. As a consequence, NEP inhibition is believed to explain the additional benefit of sacubitril/ valsartan over renin-angiotensin blockade alone (16). NEP, however, has many other substrates with diverse metabolic actions including amyloid- $\beta$ peptides (17). Therefore, some concern has been raised regarding NEP inhibition may cause or accelerate amyloid- $\beta$-related cognitive decline in patients treated with sacubitril/ valsartan. Nonetheless, this is a theoretical risk without any supporting experimental or clinical evidence (18-20). Sacubitril/valsartan is the first of a new class of drugs referred to as ARNIs (dual-acting angiotensin-receptorNEP inhibitors) that has been shown to reduce the 
morbidity and mortality of patients with HF with reduced ejection fraction (21). The rationale of this novel strategy is to inhibit the detrimental effects of renin-angiotensinaldosterone system (RAAS), and at the same time enhance the levels and activity of endogenous NPs. Therefore, at least conceptually, NEP inhibition by ARNIs might also modify the metabolic interplay between HF and CMS.

Along this line, in a recent issue of Hypertension (22), Stefan Engeli and colleagues aimed to investigate the effects of sacubitril/valsartan on whole-body and adipose tissue lipolysis and lipid oxidation. They enrolled 63 obese individuals with moderate hypertension that were randomized to 8 weeks' treatment with sacubitril/valsartan $v s$. to the metabolically neutral comparator amlodipine. They measured local tissue lipolysis during rest and exercise by microdialysis and, whole-body lipolysis through $[1,1,2,3,3-2 \mathrm{H}]$-glycerol tracer kinetics. Unexpectedly, they showed that sacubitril/valsartan treatment did not elicit relevant changes in exercise-induced lipolysis nor substrate oxidation. Conversely, other authors have demonstrated positive metabolic effects with sacubitril/valsartan therapy in obese hypertensive patients, specifically by enhancing peripheral insulin sensitivity (23). However, obesity is associated with absolute or relative NP deficiency (24), and as the authors highlighted, these results cannot be extrapolated to HF population in which the neurohormonal activity is far different. Indeed, in the work of Engeli et al. patients with history or current diagnosis of HF (NYHA IIIV) were excluded and levels of NPs of participants were not reported. Patients with HF (and high levels of NPs) are those in which sacubitril/valsartan has shown striking clinical benefits. Thus, the lack of substrate (presumed low levels of NPs) observed in the study sample may easily explain the neutral metabolic effects of ARNIs reported by Engeli et al. (22).

In a recent post-hoc analysis of the PARADIGM-HF trial (Prospective Comparison of Angiotensin Receptor Neprilysin Inhibitor with Angiotensin-Converting Enzyme Inhibitor to Determine Impact on Global Mortality and Morbidity in Heart Failure), patients who received sacubitril/valsartan exhibit a significant reduction in HbA1c [0.26\% (SD, 1.25]] compared with enalapril [0.16\% (SD, 1.40)]. Moreover, this benefit persisted during follow-up and was accompanied by a $23 \%$ and $29 \%$ reduction in new use of oral antidiabetic drugs and insulin, respectively (25).

Beyond their potential effects on diabetic control, NEP inhibition might also interfere in the positive neurohormonal feedback between HF and CMS. Recently, the leptin-aldosterone-NEP axis has been suggested to contribute importantly to the evolution and progression of obese patients with HF (26). There is evidence that NEP is expressed in adipocytes of obese individuals (27) and its circulating levels increases as obesity and insulin resistance progress (24). The overactivity of NEP in obese patients increases the breakdown of endogenous NPs, promotes adipogenesis and, thus, the secretion of leptin (28). In addition, leptin further activates the RAAS, sympathetic nervous system and directly stimulate the secretion of aldosterone leading to HF progression.

Before the results of the PARADIGM-HF trial were known, the concept and potential benefits of NEP inhibition were unfamiliar to most physicians. Nowadays, the vast majority of the cardiovascular community recognized ARNIs as a powerful therapeutic tool in HF. However, and given the "promiscuous" nature of NEP, a new chapter in HF therapy has opened and the potential role of ARNI in a broader spectrum of cardiovascular and non-cardiovascular diseases will continue to rise. It is evident that more studies are needed to unravel the real clinical relevance of the potential metabolic benefits of ARNIs.

\section{Acknowledgements}

Funding: This work was supported in part by grants from CIBER CV 16/11/00420, 16/11/00403; FEDER and PIE15/00013.

\section{Footnote}

Conflicts of Interest: The authors have no conflicts of interest to declare.

\section{References}

1. Grundy SM, Cleeman JI, Daniels SR, et al. Diagnosis and management of the metabolic syndrome: an American Heart Association /National Heart, Lung and Blood Institute Scientific Statement. Circulation 2005;112:2735-52.

2. von Bibra H, Paulus W, John Sutton M. Cardiometabolic Syndrome and Increased Risk of Heart Failure. Curr Heart Fail Rep 2016;13:219-29.

3. Volpe M, Rubattu S, Burnett J Jr. Natriuretic peptides in cardiovascular diseases: current use and perspectives. Eur Heart J 2014;35:419-25.

4. Moro C. Natriuretic peptides and fat metabolism. Curr 
Opin Clin Nutr Metab Care 2013;16:645-9.

5. Sengenes C, Bouloumie A, Hauner H, et al. Involvement of a cGMP dependent pathway in the natriuretic peptidemediated hormone-sensitive lipase phosphorylation in human adipocytes. J Biol Chem 2003;278:48617-26.

6. Tansey JT, Sztalryd C, Hlavin EM, et al. The central role of perilipin a in lipid metabolism and adipocyte lipolysis. IUBMB Life 2004;56:379-85.

7. Birkenfeld AL, Boschmann M, Moro C, et al. Lipid mobilization ith physiological atrial natriuretic peptide concentrations in humans. J Clin Endocrinol Metab 2005;90:3622-8.

8. Moro C, Crampes F, Sengenes C, et al. Atrial natriuretic peptide contributes to physiological control of lipid mobilization in humans. FASEB J 2004;18:908-10.

9. Moro C, Klimcakova E, Lolmede K, et al. Atrial natriuretic peptide inhibits the production of adipokines and cytokines linked to inflammation and insulin resistance in human subcutaneous adipose tissue. Diabetologia 2007;50:1038-47.

10. Ropero AB, Soriano S, Tuduri E, et al. The atrial natriuretic peptide and guanylyl cyclase-A system modulates pancreatic beta-cell function. Endocrinology 2010;151:3665-74.

11. Nisoli E, Tonello C, Cardile A, et al. Calorie restriction promotes mitochondrial biogenesis by inducing the expression of eNOS. Science 2005;310:314-7.

12. Engeli S, Birkenfeld AL, Badin PM, et al. Natriuretic peptides enhance the oxidative capacity of human skeletal muscle. J Clin Investig 2012;122:4675-9.

13. Tsukamoto O, Fujita M, Kato M, et al. Natriuretic peptides enhance the production of adiponectin in human adipocytes and in patients with chronic heart failure. J Am Coll Cardiol 2009;53:2070-7.

14. Vila G, Grimm G, Resl M, et al. B-Type natriuretic peptide modulates ghrelin, hunger, and satiety in healthy men. Diabetes 2012;61:2592-6.

15. Addisu A, Gower WR Jr, Landon CS, et al. B-type natriuretic peptide decreases gastric emptying and absorption. Exp Biol Med (Maywood) 2008;233:475-82.

16. Bayes-Genis A, Barallat J, Richards AM. A Test in Context: Neprilysin: Function, Inhibition, and Biomarker. J Am Coll Cardiol 2016;68:639-53.

17. Nalivaeva NN, Belyaev ND, Kerridge C, et al. Amyloidclearing proteins and their epigenetic regulation as a therapeutic target in Alzheimer's disease. Front Aging Neurosci 2014;6:235.

18. Langenickel TH, Tsubouchi C, Ayalasomayajula S, et al.
The effect of LCZ696 (sacubitril/valsartan) on amyloid- $\beta$ concentrations in cerebrospinal fluid in healthy subjects. Br J Clin Pharmacol 2016;81:878-90.

19. Schoenfeld HA, West T, Verghese PB, et al. The effect of angiotensin receptor neprilysin inhibitor, sacubitril/ valsartan, on central nervous system amyloid- $\beta$ concentrations and clearance in the cynomolgus monkey. Toxicol Appl Pharmacol 2017;323:53-65.

20. Cannon JA, Shen L, Jhund PS, et al. Dementia-related adverse events in PARADIGM-HF and other trials in heart failure with reduced ejection fraction. Eur J Heart Fail 2017;19:129-37.

21. McMurray JJ, Packer M, Desai AS, et al. Angiotensinneprilysin inhibition versus enalapril in heart failure. $\mathrm{N}$ Engl J Med 2014;371:993-1004.

22. Engeli S, Stinkens R, Heise T, et al. Effect of Sacubitril/ Valsartan on Exercise-Induced Lipid Metabolism in Patients with Obesity and Hypertension. Hypertension 2018;71:70-7.

23. Jordan J, Stinkens R, Jax T, et al. Improved Insulin Sensitivity with Angiotensin Receptor Neprilysin Inhibition in Individuals With Obesity and Hypertension. Clin Pharmacol Ther 2017;101:254-63.

24. Standeven KF, Hess K, Carter AM, et al. Neprilysin, obesity and the metabolic syndrome. Int J Obes (Lond) 2011;35:1031-40.

25. Seferovic JP, Claggett B, Seidelmann SB, et al. Effect of sacubitril/valsartan versus enalapril on glycaemic control in patients with heart failure and diabetes: a post-hoc analysis from the PARADIGM-HF trial. Lancet Diabetes Endocrinol 2017;5:333-40.

26. Packer M. Leptin-Aldosterone-Neprilysin Axis: Identification of Its Distinctive Role in the Pathogenesis of the Three Phenotypes of Heart Failure in People with Obesity. Circulation 2018;137:1614-31.

27. Schling P, Schäfer T. Human adipose tissue cells keep tight control on the angiotensin II levels in their vicinity. J Biol Chem 2002;277:48066-75.

28. Huby AC, Antonova G, Groenendyk J, et al. Adipocytederived hormone leptin is a direct regulator of aldosterone secretion, which promotes endothelial dysfunction and cardiac fibrosis. Circulation 2015;132:2134-45.

Cite this article as: de la Espriella-Juan R, Sanchis J, BayésGenís A, Núñez J. Metabolic effects of sacubitril/valsartan: are they relevant in clinical practice? Cardiovasc Diagn Ther 2018;8(4):549-551. doi: 10.21037/cdt.2018.07.05 